\title{
The $h f q$ gene is required for stress resistance and full virulence of Burkholderia cepacia to the nematode Caenorhabditis elegans
}

\section{Correspondence \\ Jorge H. Leitão \\ jorgeleitao@ist.utl.pt}

Received 1 October 2009

Revised 14 November 2009

Accepted 25 November 2009

\author{
Silvia A. Sousa, † Christian G. Ramos, † Leonilde M. Moreira \\ and Jorge H. Leitão
}

IBB - Institute for Biotechnology and Bioengineering, Centre for Biological and Chemical
Engineering, Instituto Superior Técnico, Av. Rovisco Pais, 1049-001 Lisboa, Portugal

The Burkholderia cepacia complex (Bcc) emerged as problematic opportunistic pathogens to cystic fibrosis (CF) patients. Although several virulence factors have been identified in Bcc, the knowledge of their relative contribution to Bcc pathogenicity remains scarce. In this work, we describe the identification and characterization of a B. cepacia IST408 mutant containing a disruption in the $h f q$ gene. In other bacteria, $\mathrm{Hfq}$ is a global regulator of metabolism, acting as an RNA chaperone involved in the riboregulation of target mRNAs by small regulatory non-coding RNAs (sRNAs). The B. cepacia Hfq protein was overproduced as a histidine-tagged derivative, and we show evidence that the protein forms hexamers and binds sRNAs. When provided in trans, the B. cepacia IST408 hfq gene complemented the Escherichia coli hfq mutant strain GS081. Our results also show that the $B$. cepacia hfq mutant is more susceptible to stress conditions mimicking those faced by Bcc bacteria when infecting the CF host. In addition, the $B$. cepacia $h f q$ mutant and two $h f q$ mutants derived from B. dolosa and B. ambifaria clinical isolates also exhibited a reduced ability to colonize and kill the nematode Caenorhabditis elegans, used as an infection model. These data, together with the conservation of Hfq orthologues among Bcc, strongly suggest that $\mathrm{Hfq}$ plays a major role in the survival of $\mathrm{Bcc}$ under stress conditions, contributing to the success of Bcc as CF pathogens.

\section{INTRODUCTION}

The Burkholderia cepacia complex (Bcc) is a group of at least 17 closely related bacterial species comprising human, animal and plant pathogens, as well as bioremediation and biocontrol strains (Mahenthiralingam et al., 2008; Vanlaere et al. 2008, 2009). These bacteria emerged in the early $1980 \mathrm{~s}$ as highly problematic opportunistic pathogens of patients suffering from cystic fibrosis (CF), an inherited disorder that, among other manifestations, predisposes to respiratory infections (Lyczak et al., 2002; Mahenthiralingam et al., 2005). Although B. cenocepacia and B. multivorans are the predominant species recovered from CF patients worldwide, other Bcc species have also been associated with poor clinical outcome, which is highly variable, ranging from asymptomatic carriage to the cepacia syndrome, a rapid and fatal necrotizing pneumonia (Isles et al., 1984;

†These authors contributed equally to this work.

Abbreviations: Bcc, Burkholderia cepacia complex; CF, cystic fibrosis; EPS, exopolysaccharide; IMG, Integrated Microbial Genomes; LB, Lennox broth; sRNAs, small regulatory non-coding RNAs; TB, Terrific broth.

The GenBank/EMBL/DDBJ accession number for the B. cepacia IST408 hfq sequence is EU760353.
Mahenthiralingam et al., 2005). A remarkable exception to their predominance is the infection by B. cepacia of $85 \%$ of the Portuguese CF patients who attended the major Portuguese CF Centre during the period between 2003 and 2006 (Cunha et al., 2007). Furthermore, strains of the B. cepacia species have also been associated with increased deterioration of lung function and poor clinical outcome, including the cepacia syndrome (Cunha et al., 2007). Several virulence factors have been identified in Bcc (Mahenthiralingam et al., 2005), although information on their relative contribution to the overall pathogenicity remains unclear.

In this work, we describe the isolation and characterization of a mutant from B. cepacia IST408, first identified due to its reduced ability to produce the exopolysaccharide (EPS) cepacian. Nucleotide sequence analysis revealed that this mutant carries an insertion in the promoter region of a gene similar to the Escherichia coli hfq gene. In E. coli, $h f q$ encodes a 102 aa protein that was first identified due to its requirement for the replication of the RNA plus-strand of bacteriophage $\mathrm{Q} \beta$ (Franze de Fernandez et al., 1968). The E. coli $h f q$ mutant exhibits a pleiotropic phenotype, including decreased growth rate and increased sensitivity to UV light, mutagens and oxidants (Tsui et al., 1994). 
Moreover, the synthesis of more than 50 proteins was affected in the E. coli $h f q$ mutant, partly due to the requirement of $\mathrm{Hfq}$ for the efficient translation of the rpoS gene encoding the $\sigma^{\mathrm{S}}$ sigma factor, which is expressed under a variety of stress conditions and in the stationary phase of growth (Muffler et al., 1997). The E. coli Hfq protein is a global regulator of the bacterial metabolism, acting as an RNA chaperone; it is involved in the riboregulation of target mRNAs by small regulatory non-coding RNAs (sRNAs), facilitating their interaction with target mRNAs (ValentinHansen et al., 2004). Hfq proteins have also been identified as important virulence factors in several Gram-negative bacteria, including Yersinia enterolitica, Salmonella typhimurium, Pseudomonas aeruginosa, Brucella abortus and Neisseria meningitidis, among others (Fantappiè et al., 2009; Nakao et al., 1995; Robertson \& Roop, 1999; Sittka et al., 2007; Sonnleitner et al., 2003). Here, we report the identification and cloning of the B. cepacia $h f q$ gene and show results indicating the ability of the encoded protein to form hexamers and to bind RNA molecules. Results on the requirement of a functional $h f q$ for resistance to stress conditions and survival in the nematode Caenorhabditis elegans are also presented and discussed.

\section{METHODS}

Bacterial strains, plasmids and culture conditions. Bacterial strains and plasmids used in this study are described in Table 1 . The B. cepacia IST408-SS7 mutant was obtained by random mutagenesis of B. cepacia IST408 using the plasposon pTnModOKm (Dennis \& Zylstra, 1998), using the methods described by Moreira et al. (2003), and initially selected due to its EPS-defective phenotype. Bcc and E. coli strains were maintained, respectively, in Pseudomonas isolation agar (PIA; Beckton Dickinson) plates or in Lennox broth (LB; Sigma) with $2 \%(\mathrm{w} / \mathrm{v})$ agar (Iberagar). Unless otherwise stated, liquid cultures were in $\mathrm{LB}$ at $37^{\circ} \mathrm{C}$ with orbital agitation (250 r.p.m.). Bacterial growth was followed by measuring the optical density of the cultures at $640 \mathrm{~nm}$. When appropriate, antibiotics were used at the following concentrations $\left(\mu \mathrm{g} \mathrm{ml}^{-1}\right)$ : for E. coli, ampicillin (Ap) 150; chloramphenicol $(\mathrm{Cm}) 25$; tetracycline (Tet) 10; trimethoprim $(\mathrm{Tp})$ 100; for Bcc, kanamycin (Km), 600; for B. cepacia IST408 and B. ambifaria CEP0996, Tp 200; for B. dolosa AU0158, Tp 800.

DNA manipulation techniques. Total DNA from Bcc strains was extracted from cells harvested from liquid cultures grown overnight, using the Dneasy blood \& tissue kit (Qiagen), following the manufacturer's instructions. Plasmid DNA isolation and purification, DNA amplification and restriction, and agarose gel electrophoresis were performed using standard procedures (Sambrook \& Russell, 2001). Plasmid DNA was introduced in E. coli and Bcc strains by electrotransformation as described previously (Moreira et al., 2003).

Construction of $h f q$ insertion mutants from B. cepacia IST408, B. dolosa AU0158 and B. ambifaria CEP0996. Primers P3 (5'TTTGGATCCCGTGCGGTTCAG-3') and P6 (5'-TTTGGTACCCGTCGCGAAGGA-3') containing the BamHI and KpnI restriction sites, respectively, at their $5^{\prime}$ ends, were designed to amplify the $B$. cepacia IST408 2765 bp segment containing the $h f q$ gene and the flanking regions. The amplified fragment was ligated into the BamHI/ KpnI sites of pDrive, creating pSAS1 (Table 1). The 986 bp XbaI fragment from pUC-Tp (Sokol et al., 1999) containing the Tp cassette was ligated to the single HindIII restriction site within the $h f q$ gene carried on pSAS1, creating pSAS2 (Table 1). This plasmid was introduced into B. cepacia IST408, B. dolosa AU0158 or B. ambifaria CEP0996 by electroporation (Ferreira et al., 2007). Double cross-over recombination resulting in the insertional inactivation of the $h f q$ gene in these Bcc strains was confirmed by PCR using primers P1 (5'TTTCTCGAGCACGGACGAGGC-3') and P2 (5'-AAAGGATCCAGAGCAACAAA-3').

RT-PCR experiments. Total RNA was extracted from cells of exponentially growing cultures of the wild-type B. cepacia strain IST408 or the $h f q$ mutant $B$. cepacia IST408-SS7 using the SV total RNA isolation system (Promega) followed by DNase I treatment, according to the manufacturer's instructions. The concentration and purity of extracted RNA samples was determined using a Nanodrop ND-1000 UV/visible spectrophotometer (Nanodrop Technologies).

The RT reaction was carried out using $1 \mu \mathrm{g}$ total RNA and the superscript one-step RT-PCR kit with platinum Taq (Invitrogen). Control experiments, using either total DNA or total RNA as template in the absence of reverse transcriptase, were also performed. The primer pairs P1 and P2, P3 and P4 (5'-CGGCATCGATTTCGGCAA3'), P5 (5'-CGCGTACGGGTTGTTCGAC-3') and P6, were used to investigate transcription from $h f q, h f l X$ and/or engA, respectively. Primers P2 and P3 were used to investigate $h f q-h f l X$ co-transcription.

RNA extraction, purification and labelling. mRNA and sRNA fractions were obtained from B. cepacia IST408 cells at the late exponential phase of growth, using the mirVana miRNA isolation kit (Ambion) according to the manufacturer's instructions. RNA quality was assessed using an Agilent Bioanalyser ACF (Agilent Technologies) and by visual inspection of the RNA after electrophoresis in $8 \mathrm{M}$ urea polyacrylamide gels.

sRNAs were purified from bands excised from the gel, squashed using an RNase-free pipette tip, and eluted overnight at $4{ }^{\circ} \mathrm{C}$ in TE buffer ( $\mathrm{pH}$ 8.0). Eluted sRNAs were ethanol-precipitated and resuspended in high-purity nuclease-free water. sRNAs were dephosphorylated using $1 \mathrm{U}$ calf intestinal phosphatase (New England Biolabs) following the manufacturer's instructions. sRNAs were end-labelled using the T4 polynucleotide kinase (Gibco-BRL) with fluoresceinlabelled nucleotide mix (GE Healthcare). Labelled sRNAs were ethanol-precipitated and resuspended in $25 \mu \mathrm{l}$ RNA binding buffer [containing $20 \mathrm{mM}$ Tris/ $\mathrm{HCl}$ (pH 8.0), $20 \mathrm{mM} \mathrm{KCl,} 1 \mathrm{mM} \mathrm{MgCl}$, $10 \mathrm{mM}$ sodium phosphate buffer $(\mathrm{pH} 8.0)$ and $1 \mathrm{mM} \mathrm{DTT}]$.

Hfq cloning, overproduction and purification. The B. cepacia IST408 $h f q$ gene was PCR amplified from chromosomal DNA using primers Hfq_UP_E (5'-GAATTCATGAGCAACAAAGG-3') and HF_Low_E (5'-TTTGCGATCTCGAGGGACGA-3'), containing $E c o$ RI and XhoI restriction sites, respectively. After hydrolysis, the gene was ligated into EcoRI/XhoI-digested pET23a +, creating pCGR4 (Table 1). E. coli BL21 (DE3) harbouring pCGR4 was grown at $30{ }^{\circ} \mathrm{C}$ in $100 \mathrm{ml}$ Terrific broth (TB) medium (Sambrook \& Russell, 2001) with $150 \mu \mathrm{g}$ ampicillin $\mathrm{ml}^{-1}$, until an $\mathrm{OD}_{640}$ of 0.1 was reached. Cells were harvested by centrifugation, washed once with $1 \times$ PBS buffer ( $\mathrm{pH}$ 7.2) and used to inoculate $500 \mathrm{ml} \mathrm{TB}$ medium with $150 \mu \mathrm{g}$ ampicillin $\mathrm{ml}^{-1}$. The culture was incubated at $30{ }^{\circ} \mathrm{C}$ until an $\mathrm{OD}_{640}$ of 0.5 was reached, then IPTG $(0.4 \mathrm{mM}$ final concentration) was added. After $3 \mathrm{~h}$ incubation, cells were harvested by centrifugation. Cell lysis and protein purification were performed as described previously (Sousa et al., 2007), using an Ni-NTA column (Amersham). Fractions containing Hfq were dialysed overnight at $4{ }^{\circ} \mathrm{C}$ against storage buffer $[20 \mathrm{mM}$ Tris/ $\mathrm{HCl}(\mathrm{pH} 8.0), 100 \mathrm{mM} \mathrm{KCl}$, $5 \mathrm{mM} \mathrm{MgCl}_{2}, 50 \%(\mathrm{v} / \mathrm{v})$ glycerol, $0.1 \%(\mathrm{v} / \mathrm{v})$ Tween 20 and $1 \mathrm{mM}$ DTT] using a $10 \mathrm{kDa}$ cutoff Slide-A-Lyser (Pierce). Protein concentration was estimated using the Bradford method (Bradford, 1976). Protein purity was confirmed by visual inspection of $15 \%$ 
Table 1. Bacterial strains and plasmids used in this study

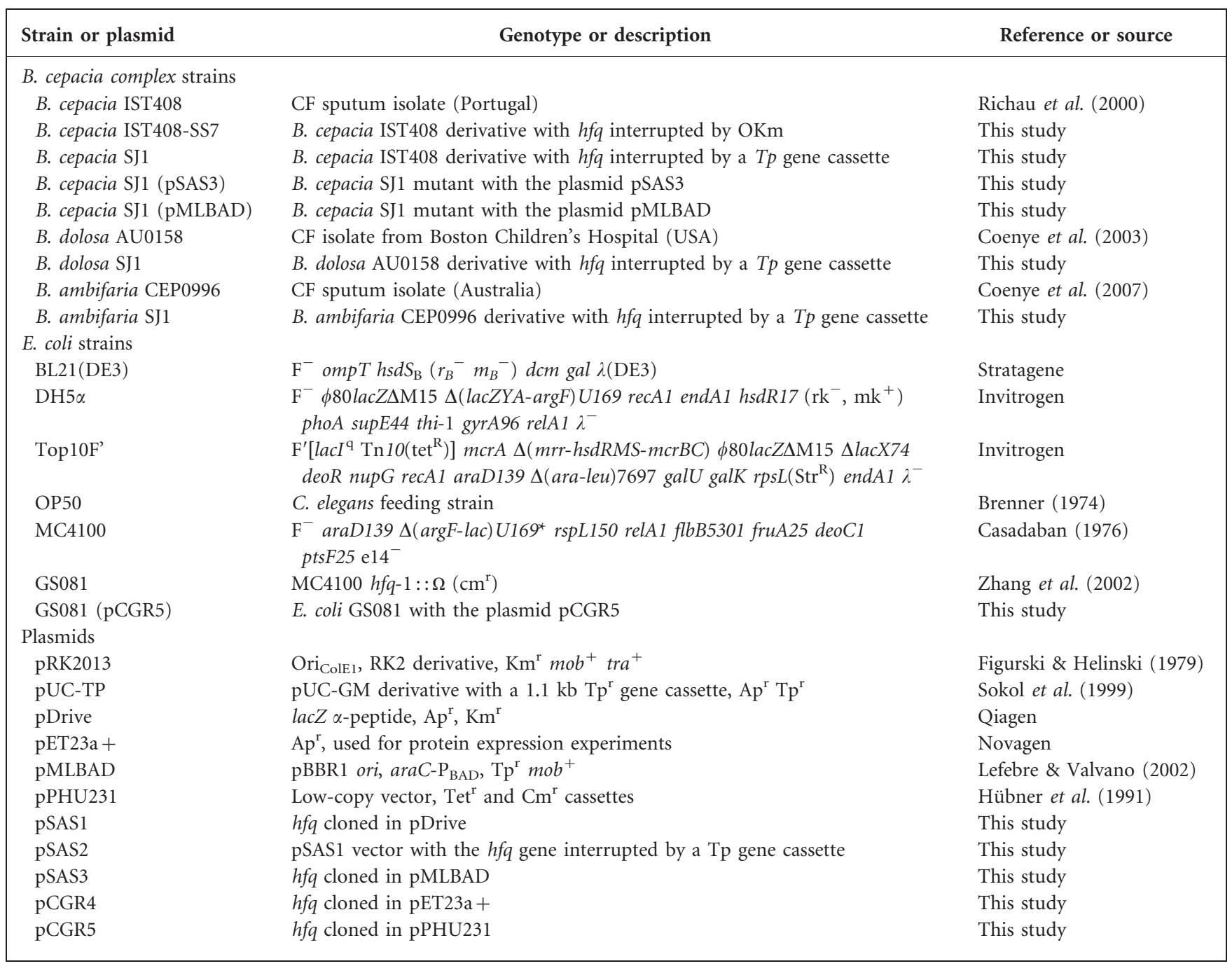

$(w / v)$ polyacrylamide gels, after electrophoresis and Coomassie blue staining.

Electrophoretic mobility shift assays (EMSAs). Purified Histagged $\mathrm{Hfq}$ was incubated at $30{ }^{\circ} \mathrm{C}$ for $15 \mathrm{~min}$ with $16 \mathrm{nmol}$ fluorescein-labelled sRNA in $25 \mu \mathrm{l}$ RNA binding buffer. Control mixtures were also prepared, lacking the purified His-tagged Hfq protein. To minimize non-specific binding, non-labelled total RNA, extracted as described above, was added in excess to each reaction. One microlitre of loading buffer (Ambion) was added to each sample and the resulting mixtures were loaded on a $10 \%(\mathrm{w} / \mathrm{v})$ polyacrylamide gel in $0.5 \times$ TBE buffer (Sambrook and Russell, 2001) containing $0.5 \%(\mathrm{v} / \mathrm{v})$ glycerol. After electrophoresis, performed at $4{ }^{\circ} \mathrm{C}$ and $350 \mathrm{~V}$, the gel was scanned using a Typhoon 8600 variable mode imager, using fluorescein emission, blue filter, $600 \mathrm{~V}$ excitation and $100 \mu \mathrm{m}$ resolution (Amersham Biosciences Europe).

In vitro cross-linking of B. cepacia His-tagged Hfq. Crosslinking experiments with purified His-tagged Hfq were performed by formaldehyde treatment, based on the methods described by Jackson (1999). Briefly, reaction mixtures containing 50-100 $\mu$ g purified Histagged Hfq in $100 \mu \mathrm{l} 20 \mathrm{mM}$ HEPES buffer ( $\mathrm{pH}$ 7.5) were treated with $5 \mu \mathrm{l}$ of a $2.3 \%(\mathrm{v} / \mathrm{v})$ freshly prepared formaldehyde solution for $2-5 \mathrm{~min}$ at $37^{\circ} \mathrm{C}$. The reaction was stopped by the addition of $10 \mu \mathrm{l}$
$1 \mathrm{M}$ Tris/ $\mathrm{HCl}$ ( $\mathrm{pH}$ 8.0). These reaction mixtures containing the crosslinked proteins were mixed with an equal volume of Laemmli sample buffer (Sambrook \& Russell, 2001), to which $2 \mu 10.1 \%$ (w/v) bromophenol blue was added. Electrophoresis was carried out using $15 \%(w / v)$ SDS-polyacrylamide gels.

The Hfq-sRNA complexes, obtained as described above for the EMSAs, were treated by UV irradiation for $5 \mathrm{~min}$ on ice; $2.5 \mathrm{U}$ RNase $\mathrm{A}$ was added (Citomed) and the mixture was incubated for $1 \mathrm{~h}$ at $37{ }^{\circ} \mathrm{C}$. The His-tagged Hfq-RNA complexes were analysed by native PAGE.

Nematode killing assays and bacterial colonization. Nematode slow-killing assays were performed and bacterial colonization of the nematodes' digestive tract was measured for B. cepacia strains IST408, the $h f q$ mutant strain SJ1 and SJ1 harbouring plasmid pSAS3, based on the methods of Moy et al. (2006) and as described previously (Sousa et al., 2008). The C. elegans mutant strain DH26 was used since this strain has a temperature-sensitive mutation, rendering worms sterile at $25{ }^{\circ} \mathrm{C}$, allowing the score of worms without the interference of progeny (Roberts \& Ward, 1982). Slow-killing experiments were carried out at least five times using five plates per experiment. E. coli OP50 was used as a negative control. Nematode killing assays and bacterial colonization were also performed for $B$. 
dolosa strains AU0158 and its $h f q$ derivative mutant, and for $B$. ambifaria CEP0996 and its $h f q$ derivative mutant.

Susceptibility to high temperature, salt, ethanol and methyl viologen. Cultures of B. cepacia strains IST408, SJ1 or SJ1(pSAS3), and E. coli strains MC4100, GS081 or GS081(pCRG5) were grown for $3 \mathrm{~h}$ at $37^{\circ} \mathrm{C}$ with orbital agitation in LB liquid media with appropriate antibiotics. Cells were then harvested by centrifugation, washed once with sterile saline $(0.9 \% \mathrm{w} / \mathrm{v})$ and resuspended in sterile water to an $\mathrm{OD}_{640}$ of 1.0 , which corresponded to $(2.0 \pm 0.1) \times 10^{8}$ c.f.u. $\mathrm{ml}^{-1}$ for B. cepacia strains and $(8.0 \pm 0.2) \times 10^{7}$ c.f.u. $\mathrm{ml}^{-1}$ for $E$. coli strains. Serial dilutions were prepared and $10 \mu \mathrm{l}$ of each dilution was spotted on to the surface of LB plates, supplemented with $5 \%$ $(\mathrm{v} / \mathrm{v})$ ethanol, $3.5 \%(\mathrm{w} / \mathrm{v}) \mathrm{NaCl}$ or $150 \mu \mathrm{M}$ methyl viologen in the case of Burkholderia strains, or $3 \%$ ethanol, $2.5 \% \mathrm{NaCl}$ or $50 \mu \mathrm{M}$ methyl viologen in the case of E. coli strains. Spots were allowed to dry and plates were incubated at 37 or $42{ }^{\circ} \mathrm{C}$ for $48 \mathrm{~h}$. Results shown are representative of at least three independent experiments.

Survival to long-term nutrient deprivation. Adequate volumes from $25 \mathrm{ml}$ liquid cultures of B. cepacia strains IST408 and SJ1 contained in $100 \mathrm{ml}$ Erlenmeyer flasks and grown overnight in LB at $37{ }^{\circ} \mathrm{C}$ with agitation, were harvested by centrifugation, washed twice with sterile saline solution and resuspended in $100 \mathrm{ml} \mathrm{M} 9$ minimal medium (Sambrook \& Russell, 2001) contained in $250 \mathrm{ml}$ Erlenmeyer flasks, supplemented with $0.002 \%(\mathrm{w} / \mathrm{v})$ each of L-leucine, Lisoleucine, L-valine, L-methionine, L-arginine, tryptophan, L-phenylalanine and L-histidine, and $0.1 \%(\mathrm{w} / \mathrm{v})$ glucose, to a final $\mathrm{OD}_{640}$ of $1.0\left[(2.0 \pm 0.1) \times 10^{8}\right.$ c.f.u. $\left.\mathrm{ml}^{-1}\right]$. Cultures were incubated for 30 days at $37^{\circ} \mathrm{C}$. The number of surviving bacteria was assessed by quantification of c.f.u. in PIA plates after $48 \mathrm{~h}$ incubation at $37{ }^{\circ} \mathrm{C}$. Results shown are representative of four independent experiments and are expressed as the percentage of the initial c.f.u. value.

Swimming motility assays. Motility assays were performed based on the methods of Bernier \& Sokol (2005). Briefly, $1 \mu$ l exponentially growing B. cepacia strains IST408, SJ1 or SJ1(pSAS3) cultures with an $\mathrm{OD}_{640}$ of 2.0 [containing $(2.30 \pm 0.05) \times 10^{9}$ c.f.u. $\mathrm{ml}^{-1}$ ] was spotted on the surface of a Swim agar plate [containing Nutrient Broth (Becton Dickinson), $0.25 \%(\mathrm{w} / \mathrm{v})$ agar and $1 \%(\mathrm{w} / \mathrm{v}) \mathrm{L}(+)-$ arabinose]. The plates were allowed to dry for $1 \mathrm{~h}$ at room temperature and then incubated for $16-22 \mathrm{~h}$ at $30^{\circ} \mathrm{C}$. Swimming zone diameters were measured and imaged in a Universal Hood II (Bio-Rad). Results are the mean values of at least three independent experiments.

Growth and quantification of EPS production. EPS production was quantified by calculating the dry weight of the ethanolprecipitated polysaccharide present in $100 \mathrm{ml}$ cell-free culture samples of B. cepacia strains IST408 and SJ1, cultivated in S liquid medium, for $72 \mathrm{~h}$ at $30^{\circ} \mathrm{C}$, with orbital agitation (250 r.p.m.), as described previously (Richau et al., 2000). EPS production was quantified as EPS weight $(\mathrm{g})$ per litre of growth medium and values given are the mean values of at least three independent determinations.

\section{RESULTS}

\section{Cloning and sequence analysis of the $B$. cepacia IST408 hfq gene}

The B. cepacia IST408-SS7 mutant was identified due to its EPS-defective phenotype during the screening of a mutant library; it is derived from the high EPS producer B. cepacia IST408 (Richau et al., 2000). The presence of a single plasposon insertion within the genome of the B. cepacia IST408-SS7 mutant was confirmed by Southern blot using EcoRI-digested chromosomal DNA and, as a probe, the $1 \mathrm{~kb}$ DNA fragment containing the kanamycin resistance cassette, obtained by ClaI restriction of pTnModOKm (data not shown). In order to identify the interrupted gene, total DNA from B. cepacia IST408-SS7 was extracted, digested with $E c o$ RI, self-ligated and used to transform $E$. coli $\mathrm{DH} 5 \alpha$. The DNA insert was sequenced with primers 5' KMR and ORIR-1 (Moreira et al., 2003). Analysis of the nucleotide sequence revealed that the plasposon was inserted $132 \mathrm{bp}$ upstream of the ATG codon of a putative gene encoding a protein $81 \%$ identical to the E. coli Hfq (Fig. 1a, c). The B. cepacia IST408 hfq-like gene was predicted to encode a 79 aa protein of $8.85 \mathrm{kDa}$ with a $\mathrm{pI}$ of 8.1. The nucleotide sequence of B. cepacia IST408 hfq was deposited in GenBank (accession no. EU760353). The B. cepacia IST408 Hfq secondary structure was predicted to contain an $\mathrm{N}$-terminal $\alpha$-helix followed by five $\beta$-strands, in an arrangement quite similar to the structure of $E$. coli Hfq (Fig. 1a, b), determined at a $2.15 \AA$ A resolution (Sauter et al., 2003) (PDB ID: 1HK9). Two conserved Sm motifs were predicted. The Sm1 motif encompasses the first three $\beta$ strands and the Sm2 motif encompasses the fourth and fifth $\beta$ strands (Fig. 1a). Sm motifs are found in Sm and Sm-like eukaryotic and archaeal proteins that form heteroheptamers and participate in RNA processing reactions (Pannone \& Wolin, 2000). The B. cepacia Hfq contains the conserved amino acid residues Gln9, Phe40, Lys57 and His58, which have been demonstrated to be involved in RNA binding by E. coli Hfq (Fig. 1a), and Gly30, which allows the bending of $\beta$ strand 2 (Sauter et al., 2003). Loops 3 and 5 are present in the central nucleotide binding pocket, as indicated in Fig. 1a (Sauter et al., 2003). In the E. coli $\mathrm{Hfq}$, the C-terminal extension after the $\beta 5$ strand is composed of 38 aa, mainly hydrophilic, with no predicted 2D structure (Sauter et al., 2003). The B. cepacia IST408 Hfq is 24 aa shorter (Fig. 1a).

\section{The $h f q$ locus is highly conserved among Bcc species}

A gene $99 \%$ identical to the B. cepacia IST408 $h f q$-like gene was found within the genome sequence of $B$. cenocepacia J2315, spanning nt 2074649-2074888 of chromosome 1 (BCAL 1879). Genes homologous to the E. coli hflC, $h f l K$, $h f l X$ and engA are also located in this locus (Fig. 1c). The putative genes $h f l C, h f l K$ and $h f l X$ and their order of appearance in this B. cenocepacia J2315 locus are similar to the corresponding homologues in E. coli (Tsui et al., 1994). In E. coli, HflX is a GTPase that binds to the ribosome $50 \mathrm{~S}$ subunit, while $h f l K$ and $h f l C$ encode membrane-associated proteases (Dutta et al., 2009), although the precise physiological roles of these proteins remain largely unknown. The engA gene upstream of $B$. cenocepacia J2315 hfq is not found in the E. coli hfq locus. In E. coli, the genes immediately upstream of $h f q$ are miaA-mutL-amiB (Tsui et al., 1994). EngA is an essential GTPase composed 
(a)

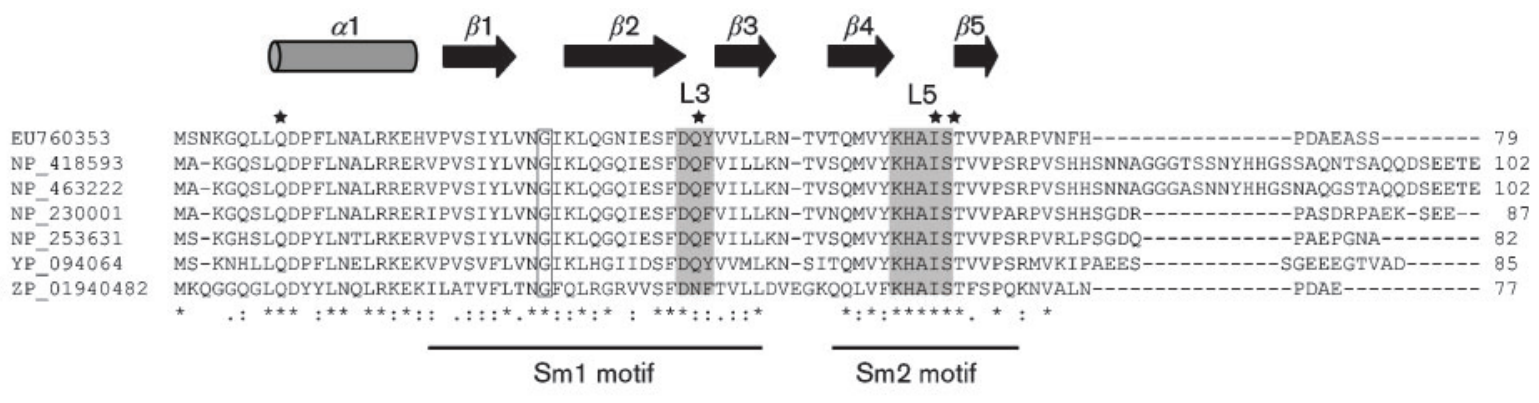

(b)

B. cepacia IST 408

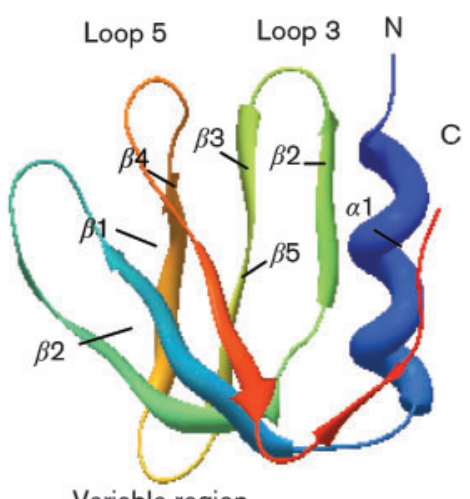

E. coli K12

Variable region

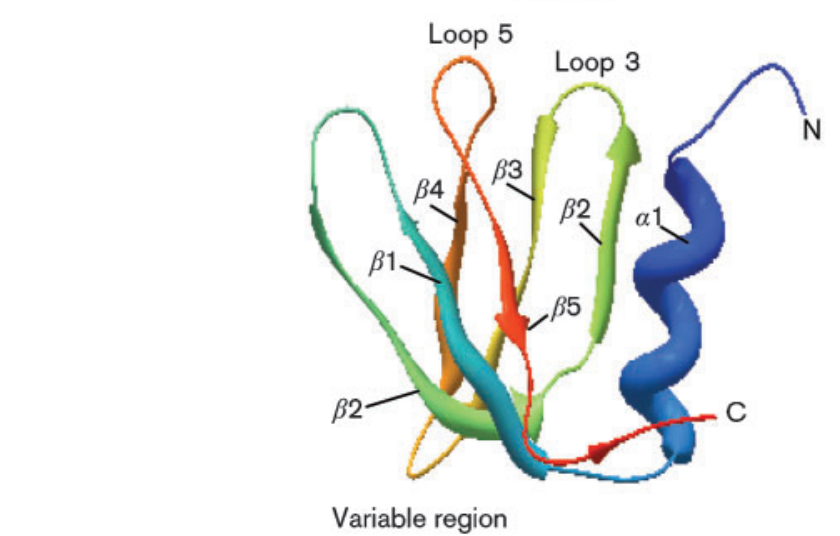

Variable region

(c)

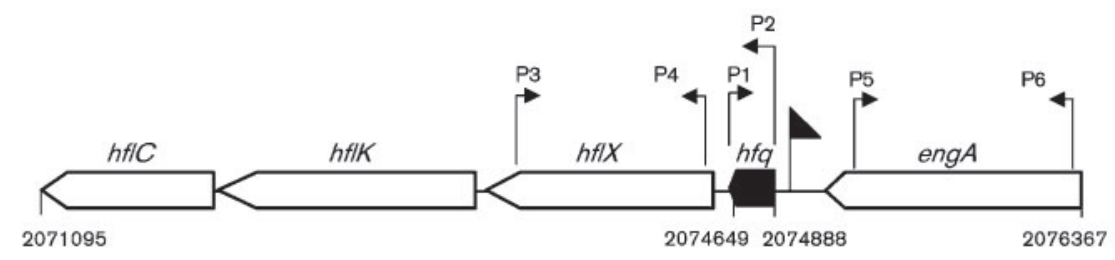

(d)
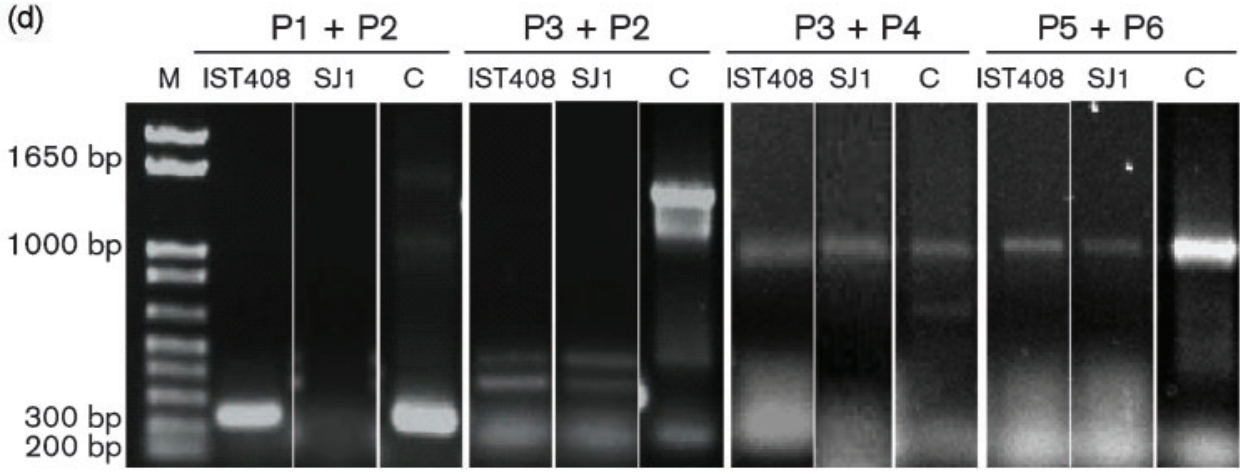

Fig. 1. B. cepacia IST408 Hfq amino acid sequence, predicted structure and genetic and transcriptional organization of the $h f q$ chromosomal locus. (a) Amino acid sequence alignment of the $B$. cepacia IST408 $\mathrm{Hfq}$ protein with the indicated bacterial $\mathrm{Hfq}$ proteins. Loops $3(\mathrm{~L} 3)$ and 5 (L5) are boxed in grey. Asterisks $\left(^{*}\right)$ above the sequence indicate conserved residues involved in RNA binding by $E$. coli $\mathrm{Hfq}$. An asterisk below the sequence indicates conserved amino acid residues; dots or double dots indicate semi-conserved or conserved substitutions, respectively. (b) Structural model of B. cepacia IST408 and E. coli K-12 (PDB ID: 1HK9) Hfq proteins. Graphics were generated using the RasWin Molecular Graphics (Windows Version 2.7.3.1). (c) Schematic representation of $B$. cenocepacia $\mathrm{J} 2315 \mathrm{hfq}$ locus. The positions of primers used for RT-PCR are indicated by arrows. The nucleotide position in chromosome 1 is indicated below the diagram. The filled triangle indicates the plasposon insertion $132 \mathrm{bp}$ upstream of the hfq ATG codon in the B. cepacia IST408-SS7 mutant. (d) Agarose gel showing the results from RT-PCR with the indicated primers. M, 1 kb plus DNA ladder (Invitrogen); IST408, B. cepacia IST408 RNA sample; SJ1, B. cepacia SJ1 RNA sample; C, B. cepacia IST408 DNA. 
of two GTP-binding domains arranged in tandem which binds to the ribosome subunits 50S, $70 \mathrm{~S}$ and 30S, and participates in ribosome biogenesis (Tomar et al., 2009).

In order to gain clues on the transcriptional organization of the identified locus in B. cepacia IST408, we performed RT assays (Fig. 1c). No DNA amplification could be detected in RT experiments performed using total RNA from $B$. cepacia IST408-SS7 and primers P1 and P2 (Fig. 1d). Similar experiments using total RNA from the wild-type strain B. cepacia IST408 led to the amplification of a $258 \mathrm{bp}$ DNA fragment corresponding to $h f q$ (Fig. 1d). These results indicate that the insertion of the plasposon $132 \mathrm{bp}$ upstream of the ATG start codon abolished $h f q$ transcription in B. cepacia IST408 (Fig. 1c). Furthermore, in E. coli, $h f q$ is part of the superoperon amiB-mutL-miaA-hfq$h f l X-h f l K-h f l C$ with a complex transcriptional organization (Tsui et al., 1994). Primers P3 to P6 were used to investigate whether $h f q$ is co-transcribed with $h f l X$ or with engA in B. cepacia IST408 and if the plasposon insertion also affected the transcription of the genes $h f l X$ and engA (Fig. 1d). No amplification products were obtained in RT experiments with primers $\mathrm{P} 2$ and $\mathrm{P} 3$, indicating that in $B$. cepacia, $h f q$ is not co-transcribed with $h f l X$ (Fig. 1d). RT experiments with primers $\mathrm{P} 1$ and $\mathrm{P} 6$ did not yield any amplification fragment, indicating that $h f q$ is not cotranscribed with engA (data not shown). Furthermore, results obtained with the primer pairs $\mathrm{P} 3$ plus $\mathrm{P} 4$, and $\mathrm{P} 5$ plus P6, also indicate that $h f l X$ and engA are both transcribed in the $h f q$ mutant strain SJ1, even in the absence of $h f q$ transcription (Fig. 1d). Together, our RT experiments demonstrate that in B. cepacia IST408, the $h f q$ gene is not co-transcribed with either of the adjacent engA or $h f l X$ genes.

The presence of B. cepacia IST408 $h f q$ homologues within the genome sequences of other Bcc strains was investigated bioinformatically, using the complete Bcc genome sequences deposited in the Integrated Microbial Genomes (IMG) database (Markowitz et al., 2008). These analyses revealed that the $h f q$ gene sequence is highly conserved among Bcc members, with an identity of at least $95 \%$ at the amino acid level (data not shown). In addition, the genetic organization engA-hfq-hflX-hflK-hflC was also conserved in all the Bcc genome sequences in IMG.

\section{B. cepacia IST408 Hfq binds to sRNAs}

To investigate whether the Hfq protein from B. cepacia IST408 has the ability to bind sRNAs, the protein was overproduced as a hexa-histidine derivative. sRNAs were isolated from B. cepacia IST408 with a commercial kit, labelled with fluorescein and incubated with $0,25,50,100$, 250 or $500 \mathrm{nmol}$ purified His-tagged Hfq. The B. cepacia IST408 His-tagged Hfq formed complexes with sRNAs, as shown by the retardation profiles of the fluoresceinlabelled sRNAs when previously incubated with 25, 50, 100 or $500 \mathrm{nmol} \mathrm{Hfq}$ (Fig. 2a). In experiments carried out using $500 \mathrm{nmol} \mathrm{Hfq}$, the Hfq-sRNA complex migrated significantly less distance than the other Hfq concentrations. We have no explanation for the observed relatively higher intensity of the Hfq-sRNA complex formed when using $500 \mathrm{nmol} \mathrm{Hfq.} \mathrm{In} \mathrm{order} \mathrm{to} \mathrm{investigate} \mathrm{the} \mathrm{possible}$ formation of Hfq multimers complexed with sRNAs, we performed UV cross-linking experiments of the purified protein after incubation with sRNAs and prior to application on the native gel. The UV cross-linked protein complexed with sRNAs was further treated with RNase and, after electrophoresis, migrated with a retardation pattern identical to the untreated protein (Fig. 2a). Based on these results which suggest the formation of $\mathrm{Hfq}$ multimers, we conducted in vitro cross-linking assays using the formaldehyde method described by Jackson (1999), followed by SDS-PAGE analysis. Two distinct bands were observed, one with an apparent molecular mass of approximately $14 \mathrm{kDa}$ and corresponding to the $\mathrm{Hfq}$ monomer, and the other form with an apparent molecular mass consistent with the formation of $\mathrm{Hfq}$ hexamers (Fig. 2b). Together, our results indicate that the B. cepacia Hfq is able to form hexamers and to bind sRNAs.

\section{B. cepacia IST408 hfq complements an E. coli hfq mutation}

Since the B. cepacia IST408 Hfq protein is 23 aa shorter than the E. coli $\mathrm{Hfq}$ protein, we decided to investigate whether B. cepacia $h f q$ complements the E. coli hfq mutant strain GS081. The B. cepacia IST408 hfq gene was PCRamplified with primers HFQcomp-UP (5'-AAGAATTCATGAGCAACAAAG-3') and HFQcomp-Low (5' - (a)

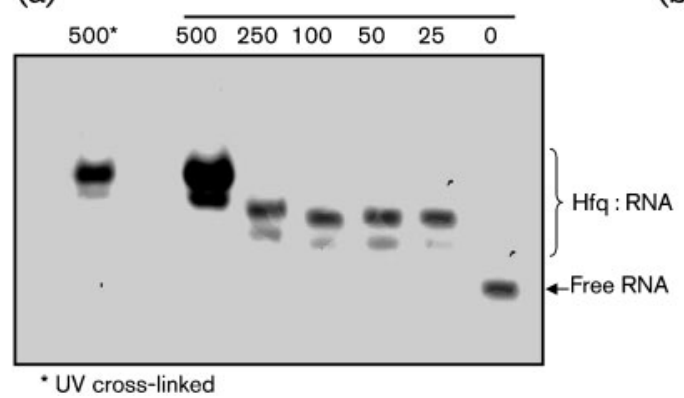

(b) $\mathrm{kDa}$

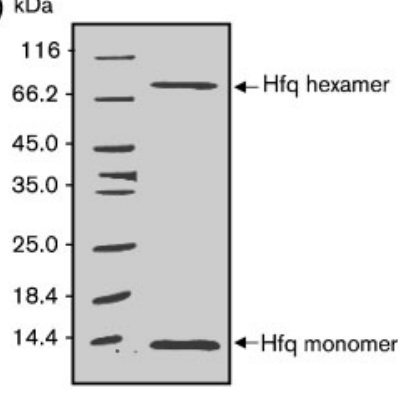

Fig. 2. The B. cepacia IST408 Hfq protein binds sRNAs and forms hexamers. (a) A clear retardation pattern is observed with increasing amounts of $\mathrm{Hfq}$. At the saturation ratio (30:1 of $\mathrm{Hfq}: \mathrm{sRNA}$ ), an enhanced retardation pattern was observed. After UV cross-linking and hydrolysis of the unbound and partially bound RNA, the same retardation was observed. (b) SDS-PAGE analysis of in vitro cross-linking of $\mathrm{Hfq}$, revealing the monomeric and hexameric forms. 
ATCTAGATTAGGACGAGGCTTC-3'), the amplified 255 bp DNA fragment was digested with EcoRI and XbaI, ligated into the pPHU231 low-copy-number cloning vector (Hübner et al., 1991), yielding plasmid pCGR5 which was introduced into E. coli GS081. pPHU231 is derived from the low-copy-number pRK290 which allows constitutive expression of $h f q$. In E. coli, Hfq levels are maintained at a characteristic level in cells at different growth phases (Ali Azam et al., 1999) and pPHU231 was used since it allows the maintenance of controlled amounts of $\mathrm{Hfq}$ sufficient to complement the mutation. E. coli GS081 harbouring the cloning vector pPHU231 was used as a control. Aliquots of $10 \mu \mathrm{l}$ of serially diluted suspensions were spotted onto the surface of $\mathrm{LB}$ and incubated for $48 \mathrm{~h}$ at $42{ }^{\circ} \mathrm{C}$ or $\mathrm{LB}$ supplemented with $3 \%$ ethanol, $2.5 \% \mathrm{NaCl}$ or $50 \mu \mathrm{M}$ methyl viologen and incubated for $48 \mathrm{~h}$ at $37^{\circ} \mathrm{C}$. As shown in Fig. 3a, the B. cepacia IST408 $h f q$ gene restored the ability of E. coli hfq mutant GS081 to survive exposure to the selected stresses, clearly indicating that the B. cepacia IST408 $h f q$ gene is functional in E. coli. The introduction of pPHU231 into E. coli GS081 led to results similar to those observed for the $h f q$ mutant strain E. coli GS081 (data not shown).

\section{hfq plays a role in stress tolerance in $B$. cepacia}

We have compared the resistance of the B. cepacia $h f q$ mutant SJ1 and the wild-type to several environmental stresses, mimicked by the addition of ethanol, $\mathrm{NaCl}$ or methyl viologen to growth medium, or by growing cultures at $42{ }^{\circ} \mathrm{C}$. The $h f q$ mutant grew poorly at $42{ }^{\circ} \mathrm{C}$ compared with the wild-type strain (Fig. 3b). The B. cepacia $h f q$ mutant also exhibited an increased susceptibility to oxidative and osmotic stresses (Fig. 3b). Results also indicate that providing the $h f q$ gene in trans partially restored the wild-type phenotypes (Fig. 3b). Higher concentrations of the stressing agents (ethanol, $\mathrm{NaCl}$ or methyl viologen) had to be used when assaying stress resistance of Bcc strains compared with those used for $E$. coli strains (Fig. 3), suggesting that Bcc strains are less sensitive to the studied stressing agents.

\section{$h f q$ is required for $B$. cepacia IST408 survival following prolonged nutrient starvation and exposure to acidic conditions}

The survival of the B. cepacia IST408 wild-type strain and of the $h f q$ mutant SJ1 to prolonged periods of nutrient starvation was compared by following each strain's growth (assessed by measuring c.f.u.) over a period of 30 days at $37^{\circ} \mathrm{C}$ in M9 minimal medium. Our results clearly demonstrate that $h f q$ plays an important role in survival following prolonged periods of starvation (Fig. 4a). We have also compared the resistance of the wild-type and the mutant strain to acidic conditions by spot-inoculating serially diluted cell suspensions in LB medium buffered at pH 5.0 with $50 \mathrm{mM}$ phosphate buffer. For the $h f q$ mutant B. cepacia SJ1, growth was only observed in the first two spots corresponding to a total of $8 \times 10^{6}$ and $8 \times 10^{5}$ c.f.u. inoculated. These results clearly indicate that a functional $h f q$ is required for $B$. cepacia survival under acidic conditions (Fig. 4b).

\section{$h f q$ is required for full virulence of $B$. cepacia IST408 and other Bcc strains to C. elegans}

In bacterial pathogens, $h f q$ deletion has been reported to affect the bacterial susceptibility to host defence mechan-
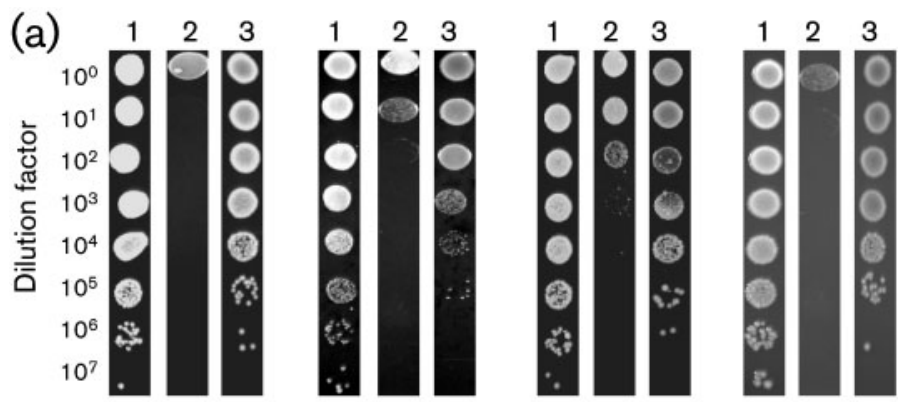

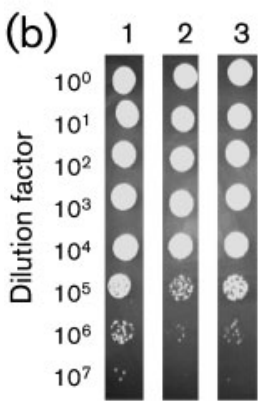

Ethanol 5\%

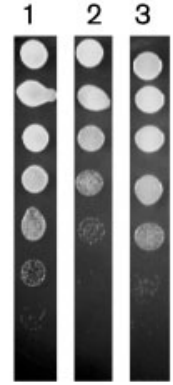

$\mathrm{NaCl} 3.5 \%$

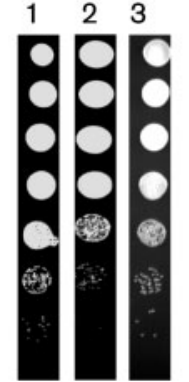

Methyl viologen $150 \mathrm{mM}$

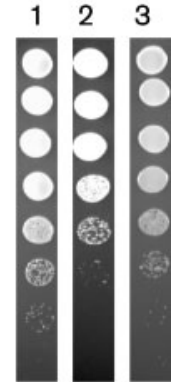

$42{ }^{\circ} \mathrm{C}$
Fig. 3. The B. cepacia IST408 hfq gene is required for stress resistance. (a) Resistance of $E$. coli wild-type strain MC4100 (lane 1), the isogenic $h f q$ mutant GS081 (lane 2) and the GS081 hfq mutant complemented with the $B$. cepacia $h f q$ gene (lane 3 ) to the indicated stresses. (b) Effect of the hfq mutation on the susceptibility of $B$. cepacia wild-type strain (lane 1), hfq mutant SJ1 (lane 2) and the complemented $h f q$ mutant SJ1(pSAS3) (lane 3) to the indicated stresses. 

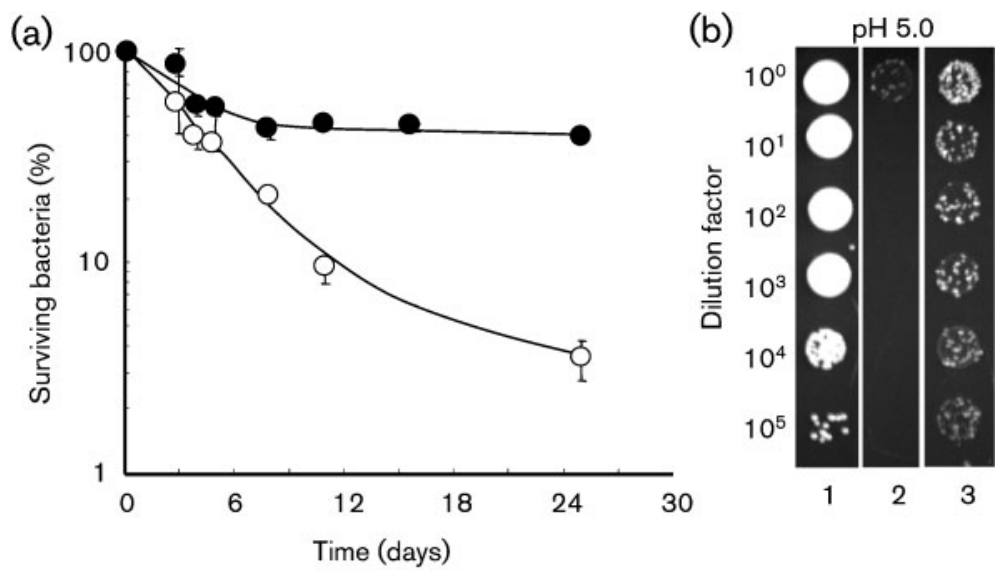

Fig. 4. The $h f q$ gene is required for survival to
nutrient starvation and acidic conditions. (a)
Ability of $B$. cepacia IST408 (O) and B.
cepacia SJ1 (O) to survive starvation on M9
minimal medium was assessed as a percent-
age of the initial c.f.u. measurement. Error bars
indicate SD. (b) Ability of B. cepacia IST408
(lane 1), B. cepacia SJ1 (lane 2) and the
complemented hfq mutant SJ1(pSAS3) (lane
3) to grow on LB solid medium buffered at
pH 5.0 with 50 mM phosphate buffer. Aliquots
(10 $\mu$ l) of cell suspension containing $8 \times 10^{8}$
c.f.u. $\mathrm{ml}^{-1}$ were inoculated per spot.

isms, with the mutants exhibiting an attenuated phenotype in infection models (Ding et al., 2004; McNealy et al., 2005; Sittka et al., 2007; Sonnleitner et al., 2003). The role played by $h f q$ on the virulence of B. cepacia IST408 was assessed using the nematode $C$. elegans, successfully used to assess the virulence traits and mechanisms of bacterial pathogens such as P. aeruginosa (Mahajan-Miklos et al., 1999) and Bcc bacteria (Cardona et al., 2005; Huber et al., 2004; Sousa et al., 2008). The bacteria surviving within the nematodes' digestive tract were also quantified by measuring c.f.u. The B. cepacia IST408 hfq mutant SJ1 exhibited an impaired ability to kill nematodes (Fig. 5a). Consistently, lower numbers of total c.f.u. were detected inside the digestive tract of worms infected with the $h f q$ mutant strain compared with worms infected with the wild-type strain (Fig. 5b). In addition, worms infected with the wild-type strain exhibited a sicker appearance when compared with those affected by the $h f q$ mutant (Fig. $5 c$ ).

In order to gain further clues about the role of $h f q$ on the pathogenicity of other Bcc species, we have prepared $h f q$ mutants from the CF isolates B. dolosa AU0158 and B. ambifaria CEP0996. Although several attempts to generate $h f q$ mutants from the CF isolates B. cenocepacia $\mathrm{J} 2315$ and $B$. multivorans LMG16660 have been carried out, we were not able to isolate $h f q$ mutants from these strains. B. dolos $a$ and B. ambifaria $h f q$ mutants also exhibited a decreased ability to kill $C$. elegans and to colonize the digestive tract of the worms (Fig. 6). The worms infected by wild-type strains of B. dolosa and B. ambifaria became thinner and exhibited a sicker appearance when compared with those infected by the respective $h f q$ mutants (Fig. 6c). Together, these results indicate a role for $h f q$ in the pathogenicity of Bcc bacteria.

\section{hfq plays a role in EPS biosynthesis and motility in $B$. cepacia IST408}

The possible role played by $h f q$ on EPS biosynthesis was assessed by comparing the amount of EPS produced by the wild-type strain B. cepacia IST408 and the $h f q$ mutant strain SJ1, in S liquid medium. The B. cepacia IST408 hfq mutant produced about half of the EPS produced by the wild-type strain (Fig. 7a), suggesting that $h f q$ plays a role in the regulation of EPS biosynthesis in B. cepacia and, most probably, in other Bcc species.

In the pathogens $S$. typhimurium and $P$. aeruginosa, disruption of $h f q$ partially impairs the bacterial cell motility (Sittka et al., 2007; Sonnleitner et al., 2003). During the colonization and infection processes of Bcc, motility endows the pathogen with a survival advantage, enhancing bacterial colonization and persistence (Tomich et al., 2002). Decreased migration (swimming) was observed for the B. cepacia $h f q$ mutant compared with the wild-type strain (Fig. 7b). The motility defect was rescued by complementation with pSAS3 (Table 1), which expressed the $h f q$ gene in trans (Fig. $7 \mathrm{~b}$ ). These results suggest that, although $\mathrm{Hfq}$ is not absolutely required for $B$. cepacia motility, it interferes with the motility of B. cepacia.

\section{A second putative $h f q$-like gene is present within the $B$. cepacia IST408 genome}

The remarkable differences observed when comparing the effects of complementation of the $h f q$ mutations in E. coli MC4100 or in B. cepacia IST408 prompted us to search for putative $h f q$ homologues in the available genome sequence of B. cenocepacia J2315. This analysis allowed the identification of BCAL1538, putatively encoding an $h f q-$ like gene. Using primers hfq2up (5'-AAGATCCATGGCCAATCCCGCAGA-3') and hfq2low (5'-TTGTCGACTTACTGGCCGTCCG-3'), designed based on the B. cenocepacia $\mathrm{J} 2315$ genome sequence, and total DNA isolated from B. cepacia IST408 as template, a $580 \mathrm{bp}$ amplicon was obtained by PCR (Fig. 8). The presence of an additional gene putatively encoding an Hfq-like protein within the genome of B. cepacia IST408 might explain the less dramatic effects of the insertional inactivation of $h f q$ in B. cepacia IST408 when compared with those observed for E. coli MC4100. Work is in progress on the functional analysis of BCAL 1538, encoding a putative Hfq-like protein. 

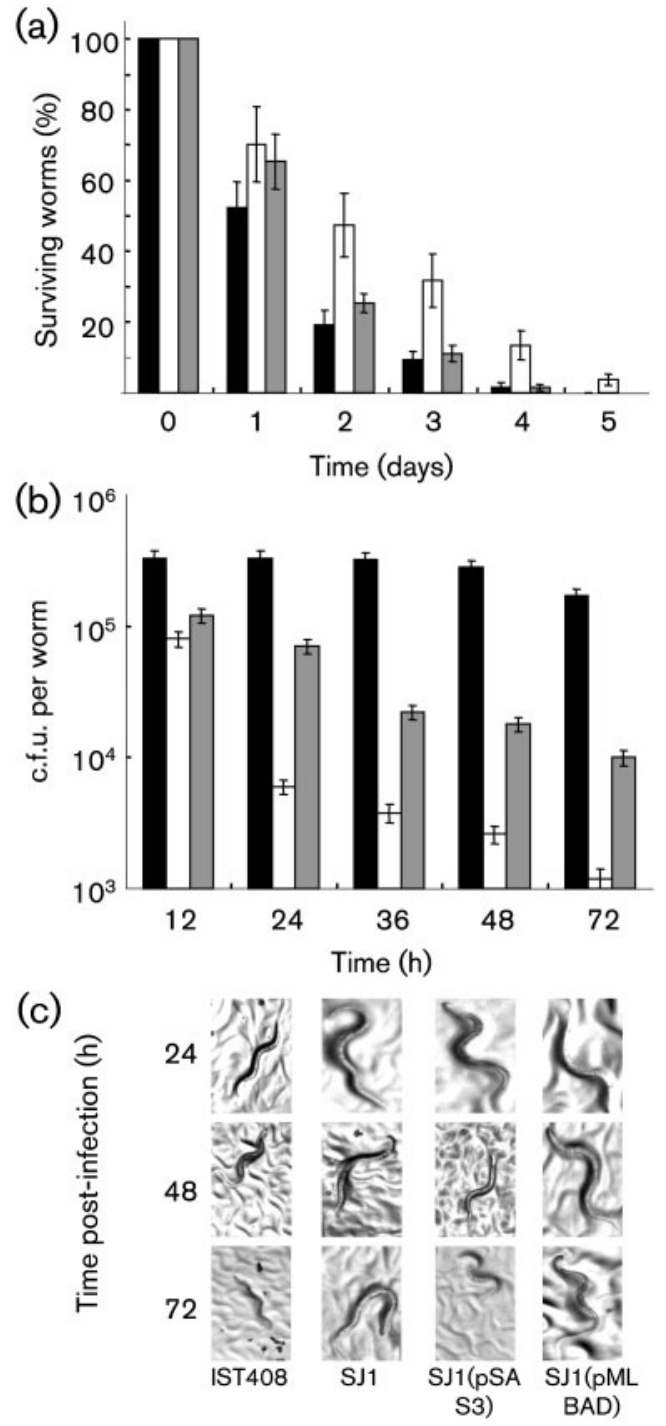

Fig. 5. The $h f q$ gene is required for $B$. cepacia IST408 virulence to the nematode $C$. elegans. Comparison of the ability of $B$. cepacia IST408 (black bars), B. cepacia SJ1 (white bars) and B. cepacia SJ1(pSAS3) (shaded bars) to kill the nematode C. elegans DH26 (a). Bacterial counts in the nematodes' intestinal tract (b) after infection for the indicated time, and photographs of randomly chosen nematodes (c) to visualize their physical status (magnification $\times 40)$. Error bars in (a) and (b) indicate SD.

\section{DISCUSSION}

In the present work, we report the identification and characterization of a B. cepacia IST408 mutant in which expression of a gene putatively encoding the RNA chaperone Hfq is abolished, as well as the characterization of the ability of the protein to form hexamers in vitro and to bind sRNA molecules. The B. cepacia IST408 hfq mutant was identified based on a strategy that led us to identify the $b c e$ cluster of genes directing the synthesis of the EPS
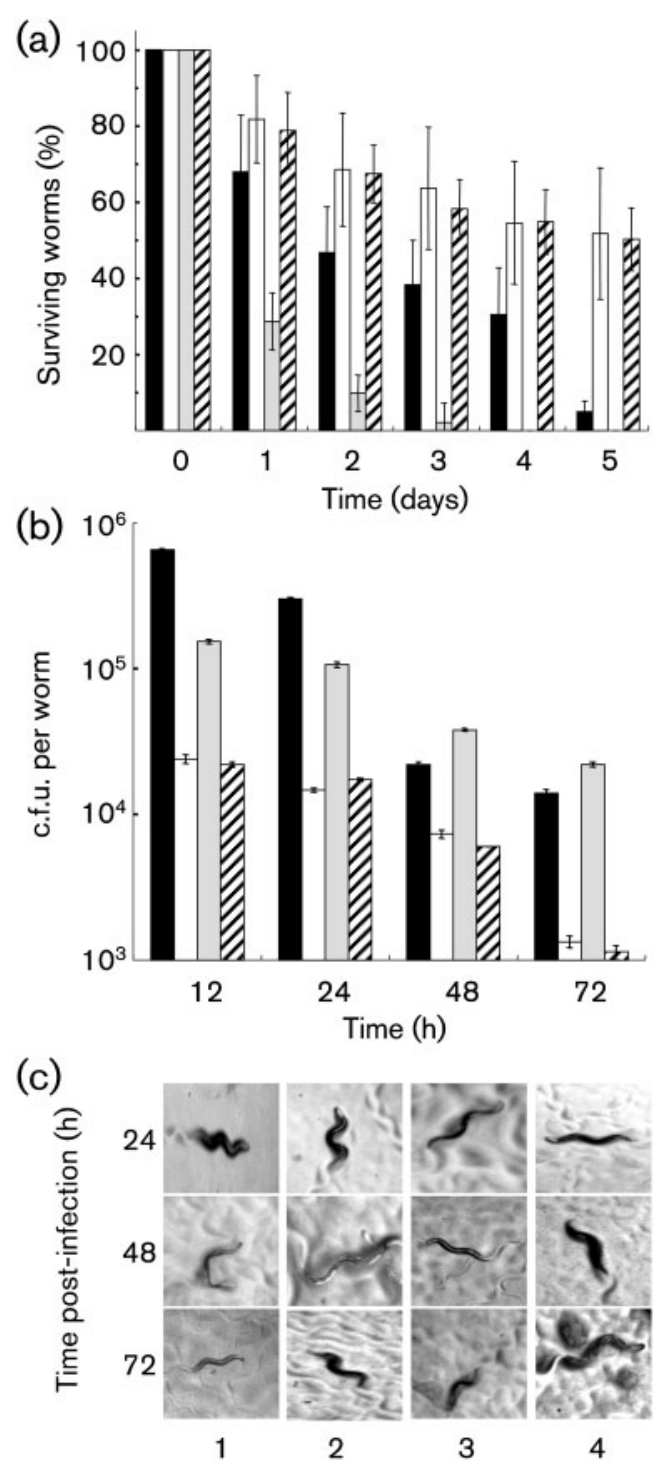

Fig. 6. The $h f q$ gene is required for full virulence of Bcc to the nematode $C$. elegans. Comparison of the ability of $B$. dolosa AU0158 (black bars/1), B. dolosa SJ1 (white bars/2), B. ambifaria CEP0996 (shaded bars/3) and B. ambifaria SJ1 (hatched bars/4) to kill C. elegans DH26 (a), the bacterial counts in the nematodes' intestinal tract (b) after infection for the indicated time, and photographs of randomly chosen nematodes (c) to visualize their physical status (magnification $\times 40$ ). Error bars in (a) and (b) indicate SD.

cepacian (Moreira et al., 2003). Although genes involved in the synthesis of EPS have been described and a few have been functionally characterized (Ferreira et al., 2007; Loutet et al., 2009; Sousa et al., 2007; Videira et al., 2005), the regulatory mechanisms underlying the regulation of EPS biosynthesis in Bcc remain unknown. A reduction of $20 \%$ in the yield of the alginate produced was reported for a $P$. aeruginosa hfq mutant (Sonnleitner et al., 2003). The B. cepacia IST408 hfq mutant produced only 


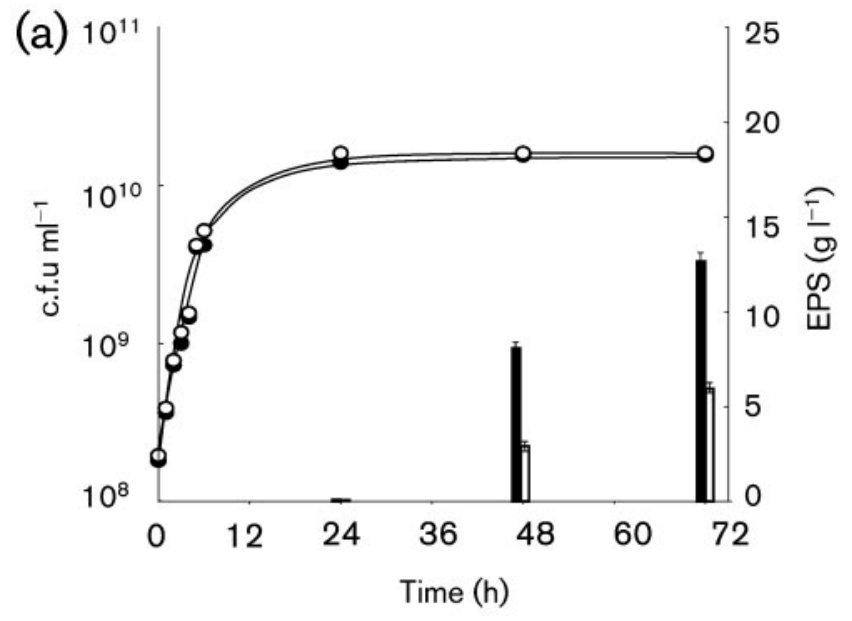

(b)

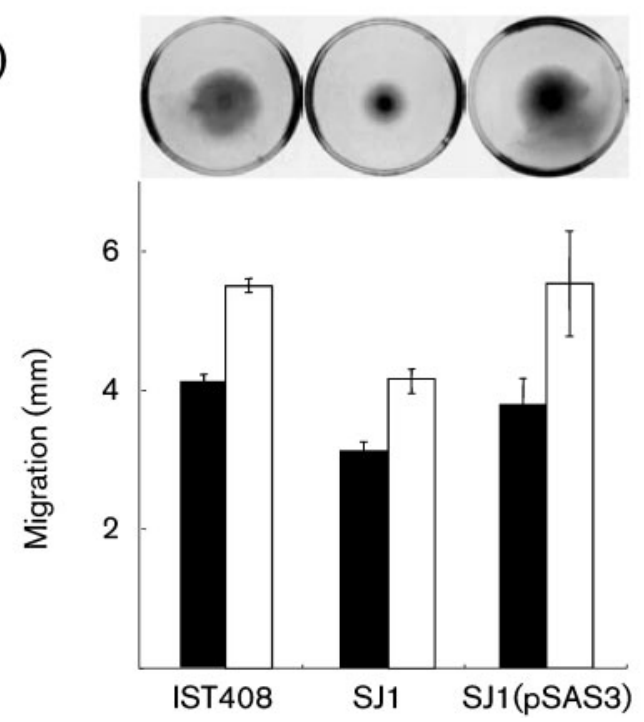

Fig. 7. Mutation of the $h f q$ gene affects EPS production and the motility of B. cepacia IST408. (a) Growth curves (circles) and EPS production (bars) by B. cepacia IST408 (black) and B. cepacia SJ1 (white). (b) Bars showing the spread of B. cepacia IST408, the $h f q$ mutant SJ 1 and SJ1(pSAS3) at $30{ }^{\circ} \mathrm{C}, 16 \mathrm{~h}$ (black bars) or $22 \mathrm{~h}$ (white bars) after inoculation onto swimming agar plates. Photographs of swimming agar plates (above) were taken after $16 \mathrm{~h}$ incubation. Error bars indicate SD.

about half the amounts of EPS produced by the wild-type strain. The molecular mechanisms linking $\mathrm{Hfq}$ and the regulation of EPS biosynthesis in B. cepacia are presently unknown. However, due to the roles reported for Hfq in other bacteria, we anticipate an indirect role, most probably involving other regulatory proteins.

In E. coli, Hfq is a highly abundant protein and mutations in the encoding gene lead to pleiotropic phenotypes, mainly due to the role of Hfq as an RNA chaperone that allows the interaction of sRNAs and their target mRNAs (Brennan \& Link, 2007). The encoding gene is located in the amiB-mutL-miaA-hfq-hflX-hflK-hflC superoperon

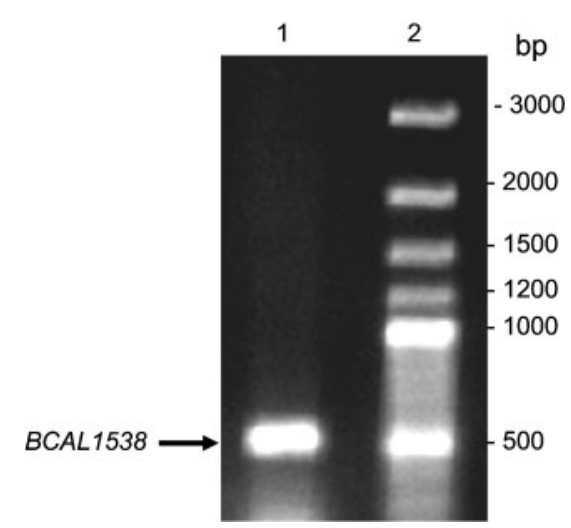

Fig. 8. Ethidium bromide-stained agarose gel showing the amplification product obtained with primers hfq2up and hfq2low, using B. cepacia IST408 total DNA as template (lane 1), demonstrating the presence of BCAL 1538 within the genome sequence of $B$. cepacia IST408. Lane 2, molecular mass marker.

with multiple $\sigma^{\mathrm{E}}$ - and $\sigma^{70}$-dependent promoters, originating various polycistronic messengers (Tsui et al., 1994). This genetic arrangement differs from that found in $B$. cepacia IST408, in which $h f q$ is located in a locus composed of the genes engA-hfq-hflX-hflK-hflC. In addition, our reverse transcription experiments also revealed that the $B$. cepacia $h f q$ locus transcriptional organization differs from that reported for E. coli, with $h f q$ being transcribed as a single monocistronic messenger independently of the adjacent $e n g A$ and $h f l X$ genes. The locus where $h f q$ locates is highly conserved among Bcc bacteria. Since in Bcc strains the locus is composed of the same genes and arranged in the same order as that described for B. cepacia IST408, we hypothesize that in Bcc bacteria, the transcription organization of the $h f q$ locus is most probably identical to that reported here for B. cepacia IST408.

Even though B. cepacia IST408 $\mathrm{Hfq}$ is 24 aa shorter at the C-terminal end compared with the E. coli Hfq protein, our results clearly indicate that the B. cepacia IST408 $h f q$ gene is able to complement the E. coli hfq mutant strain GS081. It is worth noting that results from the phenotypic characterization and complementation experiments were more impressive when compared with those observed for $B$. cepacia IST408. In light of the reported occurrence of genes in multiple copies within Bcc genomes, as is the case, for example, for the bifunctional BceA proteins with phosphomannose isomerase/GDP-mannose pyrophosphorylase activities (Sousa et al., 2007), we performed a bioinformatics search for putative Hfq proteins encoded within the B. cenocepacia J2315 genome sequence. This analysis allowed the identification of BCAL1538, putatively encoding an unusual Hfq-like protein composed of 189 aa. Whether this gene is present and functional in B. cepacia IST408 is unknown. Nevertheless, our results clearly indicate that if a BCAL1538 homologue is present within the genome of B. cepacia IST408, it does not fully 
compensate the mutation in the $h f q$ gene studied in this work. Research to functionally characterize the protein encoded by BCAL1538 is in progress.

The B. cepacia IST408 Hfq protein is able to bind sRNAs, as demonstrated by EMSAs. Since we used sRNAs purified from cells, no information is available on the specific identity and nucleotide sequences of the sRNAs that bind to B. cepacia IST408 Hfq. In E. coli, several sRNAs and their biological roles have been described, such as the OxyS (Zhang et al., 2002), which is part of the OxyR-regulated transcriptional response to oxidative stress, and RyhB, regulated by the Fur global regulator of iron acquisition genes [reviewed by Gottesman (2005)]. Although no experimental data are presently available on sRNAs and their roles in Bcc strains, 213 putative sRNAs were recently identified within the genome of B. cenocepacia J2315 based on the combination of comparative genomics and prediction of their secondary structures (Coenye et al., 2007). Work is in progress to identify sRNAs that specifically bind to Hfa, envisaging the understanding of their roles on the biology and virulence of Bcc bacteria.

The B. cepacia IST408 hfa mutant exhibited increased susceptibility to conditions related to survival under osmotic, oxidative and acidic stress conditions, reduced motility, and impaired pathogenesis to the infection model C. elegans, consistent with phenotypes described for other bacteria, such as the pathogens B. abortus (Robertson \& Roop, 1999) and N. meningitidis (Fantappiè et al., 2009). A key factor in the development of disease by $N$. meningitidis is the ability of the pathogen to colonize the hostile environment of the mucosal epithelium and to multiply within human blood. An N. meningitidis hfq mutant was attenuated in ex vivo and in vivo models of infection (Fantappiè et al., 2009). An $h f q$ mutant of the intracellular pathogen B. abortus failed to replicate within cultured murine macrophages and was rapidly cleared from the spleens and livers of mice (Robertson \& Roop, 1999). Remarkably, some aspects of the pathogenesis of Bcc organisms when infecting $\mathrm{CF}$ patients resemble the colonization and infection mechanisms used by $N$. meningitidis and $B$. abortus. The first step in the CF respiratory tract colonization and infection by Bcc is the penetration of the mucosal blanket and subsequent adherence to receptors on the epithelial cell surface, followed by invasion of the lung epithelial cell and translocation to the serosal side of the epithelium (McClean \& Callaghan, 2009). This translocation can occur through the opening and translocation through tight junctions or by attachment to lung epithelial cells receptors and invasion via intracellular vacuoles (McClean \& Callaghan, 2009). In addition, Bcc infections in CF patients seldom result in septicaemia, during which bacteria survive and multiply in human blood. During this pathogenesis process, Bcc bacteria are subject to stress conditions including nutrient deprivation, acidic conditions within the epithelial cell vacuole and exposure to reactive oxygen and nitrogen intermediates produced by professional phagocytes. The pleiotropic phenotypes observed for the B. cepacia $h f q$ mutant and the conservation of Hfq amino acid sequences within Bcc, at a level of at least $95 \%$, strongly suggest that Hfq plays a major role in the fitness of $\mathrm{Bcc}$ bacteria and survival when infecting CF patients, thus contributing to the success of these bacteria as pathogens in CF.

\section{ACKNOWLEDGEMENTS}

The authors gratefully acknowledge Gisela Storz for kindly providing E. coli strains MC4100 and GS081, and the Caenorhabditis elegans Genetics Center for the kind gift of C. elegans DH26. This work was partially funded by FEDER and FCT, Portugal (contract PTDC/BIAMIC/65210/2006, and a post-doctoral grant to S.A.S.). C. G.R. acknowledges a doctoral grant from Fundação Calouste Gulbenkian (Portugal).

\section{REFERENCES}

Ali Azam, T., Iwata, A., Nishimura, A., Ueda, S. \& Ishihama, A. (1999). Growth-phase-dependent variation in protein composition of the Escherichia coli nucleoid. J Bacteriol 181, 6361-6370.

Bernier, S. P. \& Sokol, P. A. (2005). Use of suppression-subtractive hybridization to identify genes in the Burkholderia cepacia complex that are unique to Burkholderia cenocepacia. J Bacteriol 187, 52785291.

Bradford, M. M. (1976). A rapid and sensitive method for the quantification of microgram quantities of protein utilizing the principle of protein-dye binding. Anal Biochem 72, 248-254.

Brennan, R. G. \& Link, T. M. (2007). Hfq structure, function and ligand binding. Curr Opin Microbiol 10, 125-133.

Brenner, S. (1974). The genetics of Caenorhabditis elegans. Genetics 77, 71-94.

Cardona, S. T., Wopperer, J., Eberl, L. \& Valvano, M. A. (2005). Diverse pathogenicity of Burkholderia cepacia complex strains in the Caenorhabditis elegans host model. FEMS Microbiol Lett 250, 97-104.

Casadaban, M. J. (1976). Transposition and fusion of the lac genes to selected promoters in Escherichia coli using bacteriophage lambda and Mu. J Mol Biol 104, 541-555.

Coenye, T., Vandamme, P., LiPuma, J. J., Govan, J. R. \& Mahenthiralingam, E. (2003). Updated version of the Burkholderia cepacia complex experimental strain panel. J Clin Microbiol 41, 27972798.

Coenye, T., Drevinek, P., Mahenthiralingam, E., Shah, S. A., Gill, R. T., Vandamme, P. \& Ussery, D. W. (2007). Identification of putative noncoding RNA genes in the Burkholderia cenocepacia J2315 genome. FEMS Microbiol Lett 276, 83-92.

Cunha, M. V., Pinto-de-Oliveira, A., Meirinhos-Soares, L., Salgado, M. J., Melo-Cristino, J., Correia, S., Barreto, C. \& Sá-Correia, I. (2007). Exceptionally high representation of Burkholderia cepacia among B. cepacia complex isolates recovered from the major Portuguese cystic fibrosis center. J Clin Microbiol 45, 1628-1633.

Dennis, J. J. \& Zylstra, G. J. (1998). Plasposons: modular self-cloning minitransposon derivatives for rapid genetic analysis of Gramnegative bacterial genomes. Appl Environ Microbiol 64, 2710-2715.

Ding, Y., Davis, B. M. \& Waldor, M. K. (2004). Hfq is essential for Vibrio cholerae virulence and downregulates $\sigma$ expression. Mol Microbiol 53, 345-354. 
Dutta, D., Bandyopadhyay, K., Datta, A. B., Sardesai, A. A. \& Parrack, P. (2009). Properties of HflX, an enigmatic protein from Escherichia coli. J Bacteriol 191, 2307-2314.

Fantappiè, L., Metruccio, M. M., Seib, K. L., Oriente, F., Cartocci, E., Ferlicca, F., Giuliani, M. M. M., Scarlato, V. \& Delany, I. (2009). The RNA chaperone Hfq is involved in stress response and virulence in Neisseria meningitidis and is a pleiotropic regulator of protein expression. Infect Immun 77, 1842-1853.

Ferreira, A. S., Leitão, J. H., Sousa, S. A., Cosme, A. M., Sá-Correia, I. \& Moreira, L. M. (2007). Functional analysis of Burkholderia cepacia genes $b c e D$ and $b c e F$, encoding a phosphotyrosine phosphatase and a tyrosine autokinase, respectively: role in exopolysaccharide biosynthesis and biofilm formation. Appl Environ Microbiol 73, 524534.

Figurski, D. H. \& Helinski, D. R. (1979). Replication of an origincontaining derivative of plasmid RK2 dependent on a plasmid function provided in trans. Proc Natl Acad Sci U S A 76, 1648-1652.

Franze de Fernandez, M. T., Eoyang, L. \& August, J. T. (1968). Factor fraction required for the synthesis of bacteriophage $\mathrm{Q} \beta$-RNA. Nature 219, 588-590.

Gottesman, S. (2005). Micros for microbes: non-coding regulatory RNAs in bacteria. Trends Genet 21, 399-404.

Huber, B., Feldmann, F., Köthe, M., Vandamme, P., Wopperer, J., Riedel, K. \& Eberl, L. (2004). Identification of a novel virulence factor in Burkholderia cenocepacia required for efficient slow killing of Caenorhabditis elegans. Infect Immun 72, 7220-7230.

Hübner, P., Willison, J. C., Vignais, P. M. \& Bickle, T. A. (1991). Expression of regulatory nif genes in Rhodobacter capsulatus. J Bacteriol 173, 2993-2999.

Isles, A., Maclusky, I., Corey, M., Gold, R., Prober, C., Fleming, P. \& Levison, H. (1984). Pseudomonas cepacia infection in cystic fibrosis: an emerging problem. J Pediatr 104, 206-210.

Jackson, V. (1999). Formaldehyde cross-linking for studying nucleosomal dynamics. Methods 17, 125-139.

Lefebre, M. D. \& Valvano, M. A. (2002). Construction and evaluation of plasmid vectors optimized for constitutive and regulated gene expression in Burkholderia cepacia complex isolates. Appl Environ Microbiol 68, 5956-5964.

Loutet, S. A., Bartholdson, S. J., Govan, J. R., Campopiano, D. J. \& Valvano, M. A. (2009). Contributions of two UDP-glucose dehydrogenases to viability and polymyxin B resistance of Burkholderia cenocepacia. Microbiology 155, 2029-2039.

Lyczak, J. B., Cannon, L. C. \& Pier, G. P. (2002). Lung infections associated with cystic fibrosis. Clin Microbiol Rev 15, 194-222.

Mahajan-Miklos, S., Tan, M. W., Rahme, L. G. \& Ausubel, F. M. (1999). Molecular mechanisms of bacterial virulence elucidated using a Pseudomonas aeruginosa-Caenorhabditis elegans pathogenesis model. Cell 96, 47-56.

Mahenthiralingam, E., Urban, T. A. \& Goldberg, J. B. (2005). The multifarious, multireplicon Burkholderia cepacia complex. Nat Rev Microbiol 3, 144-156.

Mahenthiralingam, E., Baldwin, A. \& Dowson, C. G. (2008). Burkholderia cepacia complex bacteria: opportunistic pathogens with important natural biology. J Appl Microbiol 104, 1539-1551.

Markowitz, V. M., Szeto, E., Palaniappan, K., Grechkin, Y., Chu, K., Chen, I. A., Dubchak, I., Anderson, I., Lykidis, A. \& other authors (2008). The integrated microbial genomes (IMG) system in 2007: data content and analysis tool extensions. Nucleic Acids Res 36, D528-D533.

McClean, S. \& Callaghan, M. (2009). Burkholderia cepacia complex: epithelial cell-pathogen confrontations and potential for therapeutic intervention. J Med Microbiol 58, 1-12.
McNealy, T. L., Forsbach-Birk, V., Shi, C. \& Marre, R. (2005). The Hfq homolog in Legionella pneumophila demonstrates regulation by LetA and RpoS and interacts with the global regulator CsrA. J Bacteriol 187, 1527-1532.

Moreira, L. M., Videira, P. A., Sousa, S. A., Leitão, J. H., Cunha, M. V. \& Sá-Correia, I. (2003). Identification and physical organization of the gene cluster involved in the biosynthesis of Burkholderia cepacia complex exopolysaccharide. Biochem Biophys Res Commun 312, 323333.

Moy, T. I., Ball, A. R., Anklesaria, Z., Casadei, G., Lewis, K. \& Ausubel, F. M. (2006). Identification of novel antimicrobials using a live-animal infection model. Proc Natl Acad Sci U S A 103, 10414-10419.

Muffler, A., Traulsen, D. D., Fischer, D., Lange, R. \& Hengge-Aronis, R. (1997). The RNA-binding protein HF-I plays a global regulatory role, which is largely, but not exclusively, due to its role in expression of the sigma S subunit of RNA polymerase in Escherichia coli. J Bacteriol 179, 297-300.

Nakao, H., Watanabe, H., Nakayama, S. \& Takeda, T. (1995). yst gene expression in Yersinia enterolitica is positively regulated by a chromosomal region that is highly homologous to Escherichia coli host factor 1 gene ( $h f q$ ). Mol Microbiol 18, 859-865.

Pannone, B. K. \& Wolin, S. L. (2000). RNA degradation: Sm-like proteins wRING the neck of mRNA. Curr Biol 10, R478-R481.

Richau, J. A., Leitão, J. H., Correia, M., Lito, L., Salgado, M. J., Barreto, C., Cescutti, P. \& Sá-Correia, I. (2000). Molecular typing and exopolysaccharide biosynthesis of Burkholderia cepacia isolates from a Portuguese cystic fibrosis center. J Clin Microbiol 38, 1651-1655.

Roberts, T. M. \& Ward, S. (1982). Membrane flow during nematode spermiogenesis. J Cell Biol 92, 113-120.

Robertson, G. T. \& Roop, R. M., Jr (1999). The Brucella abortus host factor 1 (HF-I) protein contributes to stress resistance during stationary phase and is a major determinant of virulence in mice. Mol Microbiol 34, 690-700.

Sambrook, J. \& Russell, D. W. (2001). Molecular Cloning: a Laboratory Manual, 3rd edn. Cold Spring Harbor, NY: Cold Spring Harbor Laboratory.

Sauter, C., Basquin, J. \& Suck, D. (2003). Sm-like proteins in Eubacteria: the crystal structure of the Hfq protein from Escherichia coli. Nucleic Acids Res 31, 4091-4098.

Sittka, A., Pfeiffer, V., Tedin, K. \& Vogel, J. (2007). The RNA chaperone Hfq is essential for the virulence of Salmonella typhimurium. Mol Microbiol 63, 193-217.

Sokol, P. A., Darling, P., Woods, D. E., Mahenthiralingam, E. \& Kooi, C. (1999). Role of ornibactin biosynthesis in the virulence of Burkholderia cepacia: characterization of $p v d A$, the gene encoding L-ornithine $N^{5}$ oxygenase. Infect Immun 67, 4443-4455.

Sonnleitner, E., Hagens, S., Rosenau, F., Wilhelm, S., Habel, A., Jager, K. E. \& Blasi, U. (2003). Reduced virulence of a $h f q$ mutant of Pseudomonas aeruginosa O1. Microb Pathog 35, 217-228.

Sousa, S. A., Moreira, L. M., Wopperer, J., Eberl, L., Sá-Correia, I. \& Leitão, J. H. (2007). The Burkholderia cepacia bceA gene encodes a protein with phosphomannose isomerase and GDP-D-mannose pyrophosphorylase activities. Biochem Biophys Res Commun 353, 200206.

Sousa, S. A., Ramos, C. G., Almeida, F., Meirinhos-Soares, L., Wopperer, J., Schwager, S., Eberl, L. \& Leitão, J. H. (2008). Burkholderia cenocepacia J2315 acyl carrier protein: a potential target for antimicrobials' development? Microb Pathog 45, 331-336.

Tomar, S. K., Dhimole, N., Chatterjee, M. \& Prakash, B. (2009). Distinct GDP/GTP bound states of the tandem G-domains of EngA regulate ribosome binding. Nucleic Acids Res 37, 2359-2370. 
Tomich, M., Herfst, C. A., Golden, J. W. \& Mohr, C. D. (2002). Role of flagella in host cell invasion by Burkholderia cepacia. Infect Immun 70, 1799-1806.

Tsui, H.-C. T., Leung, H.-C. E. \& Winkler, M. E. (1994). Characterization of broadly pleiotropic phenotypes caused by an $h f q$ insertion mutation in Escherichia coli K-12. Mol Microbiol 13, 35-49.

Valentin-Hansen, P., Eriksen, M. \& Udesen, C. (2004). The bacterial Sm-like protein Hfq: a key player in RNA transactions. Mol Microbiol 51, 1525-1533.

Vanlaere, E., Lipuma, J. J., Baldwin, A., Henry, D., De Brandt, E., Mahenthiralingam, E., Speert, D. P., Dowson, C. \& Vandamme, P. (2008). Burkholderia latens sp. nov., Burkholderia diffusa sp. nov., Burkholderia arboris sp. nov., Burkholderia seminalis sp. nov. and Burkholderia metallica sp. nov., novel species within the Burkholderia cepacia complex. Int J Syst Evol Microbiol 58, 1580-1590.
Vanlaere, E., Baldwin, A., Gevers, D., Henry, D., De Brandt, E., LiPuma, J. J., Mahenthiralingam, E., Speert, D. P., Dowson, C. \& Vandamme, P. (2009). Taxon K, a complex within the Burkholderia cepacia complex comprises at least two novel species: Burkholderia contaminans sp. nov. and Burkholderia lata sp. nov. Int J Syst Evol Microbiol 59, 102-111.

Videira, P. A., Garcia, A. P. \& Sá-Correia, I. (2005). Functional and topological analysis of the Burkholderia cenocepacia priming glucosyltransferase $\mathrm{BceB}$, involved in the biosynthesis of the cepacian exopolysaccharide. J Bacteriol 187, 5013-5018.

Zhang, A., Wassarman, K. M., Ortega, J., Steven, A. C. \& Storz, G. (2002). The Sm-like Hfq protein increases OxyS RNA interaction with target mRNAs. Mol Cell 9, 11-22.

Edited by: P. Cornelis 